\title{
Historical data provide new insights into response and adaptation of maize production systems to climate change/variability in China
}

\author{
Fulu Tao ${ }^{\mathrm{a}, *}$, Zhao Zhang ${ }^{\mathrm{b}}$, Shuai Zhang ${ }^{\mathrm{a}}$, Reimund P. Rötter ${ }^{\mathrm{c}}$, Wenjiao Shi ${ }^{\mathrm{a}}$, \\ Dengpan Xiao ${ }^{\mathrm{a}}$, Yujie Liu ${ }^{\mathrm{a}}$, Meng Wang ${ }^{\mathrm{a}}$, Fengshan Liu ${ }^{\mathrm{a}}$, He Zhang ${ }^{\mathrm{a}}$ \\ a Institute of Geographical Sciences and Natural Resources Research, Chinese Academy of Sciences, Beijing 100101, China \\ b State Key Laboratory of Earth Surface Processes and Resource Ecology, Beijing Normal University, Beijing 100875, China \\ ${ }^{\mathrm{c}}$ Natural Resources Institute Finland (Luke), FI-01301 Vantaa, Finland
}

\section{A R T I C L E I N F O}

\section{Article history:}

Received 6 February 2015

Received in revised form 14 October 2015

Accepted 14 October 2015

Available online 31 October 2015

\section{Keywords:}

China

Climate variability

Grain yield

Impact

Maize

\begin{abstract}
A B S T R A C T
Extensive studies had been conducted to investigate the impacts of climate change on maize growth and yield in recent decades; however, the dynamics of crop husbandry in response and adaptation to climate change were not taken into account. Based on field observations spanning from 1981 to 2009 at 167 agricultural meteorological stations across China, we found that solar radiation and temperature over the observed maize growth period had decreasing trends during 1981-2009, and maize yields were positively correlated with these climate variables in major production regions. The decreasing trends in solar radiation and temperature during maize growth period were mainly ascribed to the adoption of late maturity cultivars with longer reproductive growth period (RGP). The adoption of late maturing cultivars with longer RGP contributed substantially to grain yield increase during the last three decades. The climate trends during maize growth period varied among different production areas. During 1981-2009, decreases in mean temperature, precipitation and solar radiation over maize growth period jointly reduced yield most by $13.2-17.3 \%$ in southwestern China, by contrast in northwestern China increases in mean temperature, precipitation and solar radiation jointly increased yield most by 12.9-14.4\%. Our findings highlight that the adaptations of maize production system to climate change through shifts of sowing date and genotypes are underway and should be taken into accounted when evaluating climate change impacts.
\end{abstract}

(C) 2015 Elsevier B.V. All rights reserved.

\section{Introduction}

Global maize production and consumption have shown constant increases in the past few decades (FAO, 2012). However, maize yield has been documented to be quite vulnerable to climate change/variability in global major maize production regions, using both crop models (Challinor et al., 2007; Tao et al., 2009; Tao and Zhang, 2011) and statistical approaches (Tao et al., 2004, 2012; Schlenker and Roberts, 2009; Cairns et al., 2012; Lobell et al., 2011a,b, 2013; Wang et al., 2014). Therefore, the ability to maintain rates of yield increase in the face of climate change has increasingly been of concern (Cassman, 2007; IPCC 2014; Schlenker and Roberts, 2009; Battisti and Naylor, 2009; de Lattre-Gasquet et al., 2009; Godfray et al., 2010; Olesen et al., 2011; Elsgaard et al., 2012; Lobell et al., 2013). China produces more than $20 \%$ of global annual

\footnotetext{
* Corresponding author.

E-mail address: taofl@igsnrr.ac.cn (F. Tao).
}

maize and is the second consumer of maize in the world. Hence, the impacts of climate change on maize production in this country have global effects.

Extensive studies document that temperature has increased significantly whereas precipitation trends have been smaller during crop growing season since 1980 at broad regions of the world (Lobell et al., 2011), including China (Tao et al., 2012; Zhang et al., 2015). Increases in mean temperature, extreme high temperature (above $30^{\circ} \mathrm{C}$ ) stress and drought stress have been indicated to be the major challenges for maize productivity in the face of climate change (Bolanos and Edmeades, 1996; Crafts-Brandner and Salvucci, 2002; IPCC, 2014; Battisti and Naylor, 2009; Lobell et al., 2011b, 2013; Olesen et al., 2011; Tao et al., 2012). Increase in mean temperature can reduce crop growth period and subsequently reduce grain yield (IPCC, 2014). Extreme high temperature stress can desiccate pollen and increase kernel abortion during flowering (Bolanos and Edmeades, 1996; Rattalino Edreira et al., 2011), reduce net photosynthesis rates (Crafts-Brandner and Salvucci, 2002), increase vapor pressure deficit and aggravate drought stress 


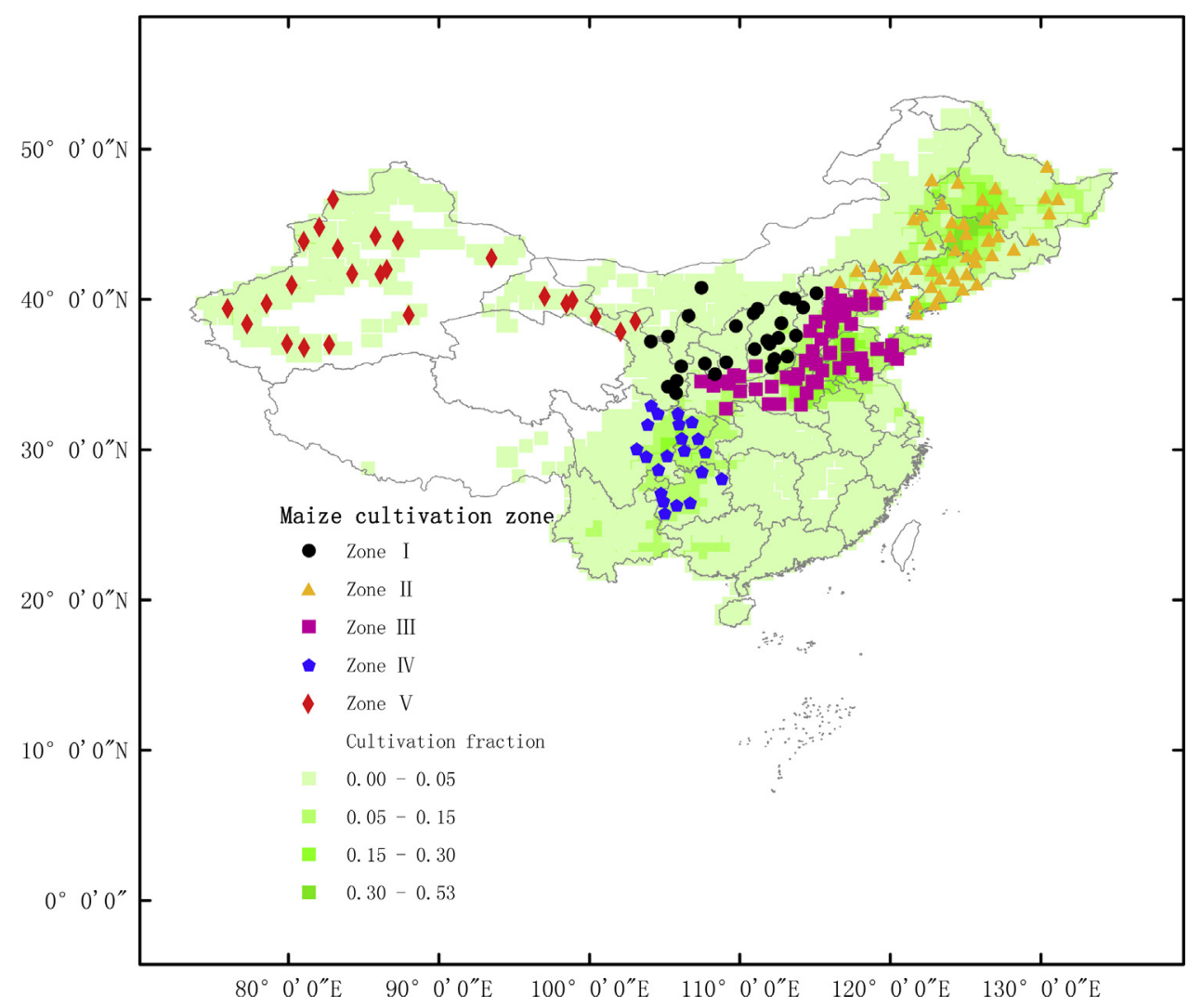

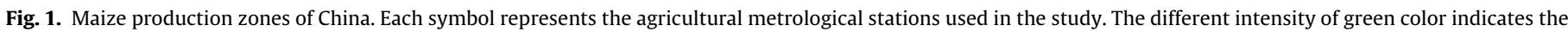

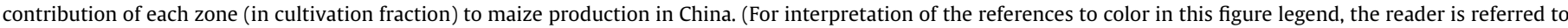
the web version of this article.)

(Lobell et al., 2013). The latter mechanism has been indicated to play an important role in affecting maize productivity in some regions of U.S. (Lobell et al., 2013), Africa (Lobell et al., 2011b) and China (Tao et al., 2012) in the past decades.

Nevertheless, the mechanisms, extent and degree of climate impacts on crop growth and productivity under contrasting environments and climate conditions are still imperfectly understood (Lobell et al., 2011b, 2013; Butler and Huybers, 2013; Licker et al., 2013). This particularly applies to the continuous adjustments and adaptations of farmers to climate change such as shifts of sowing dates and cultivars (Welch et al., 2010; Siebert and Ewert, 2012, 2014; Tao et al., 2014a). Crop models and statistical approaches are commonly used to address climate impacts on crop growth and grain yield, both of which, however, have some shortcomings. Crop models do not include potentially relevant processes such as impacts of extremely high temperatures (Lobell and Burke, 2009; Tao et al., 2009; Rötter et al., 2011; Asseng et al., 2013; Ruane et al., 2013; Bassu et al., 2014). Statistical approaches are frequently limited by the quantity and quality of data (Lobell and Burke, 2009). Furthermore, most statistical studies assess climate change and its potential impacts by correlating crop yields at a state or nation from census data with seasonal climate for the same calendar period throughout the whole time series without accounting for the dynamics of cropping systems (i.e., changes of agronomic management practices) (Reidsma et al., 2010; Welch et al., 2010; Tao et al., 2014a). In fact, many farmers select crop cultivars, shift sowing dates and agronomic practices based on the expected meteorological conditions (Tao et al., 2014b). The actual impacts of climate change and variability are largely dependent on farm level response, to accurately understand impacts and adaptation, assessments should consider responses at different levels of organization (Reidsma et al., 2010; Welch et al., 2010).
Historical data from farmer-managed fields would allow us to establish how farmers made changes of agricultural practices based on the weather they observed (Welch et al., 2010; Tao et al., 2014a). In the present study, field observations at 167 agricultural meteorological stations across China (Fig. 1, Table 1) spanning from 1981 to 2009 were used to quantify maize grain yield response considering changes of maize husbandry at different regions of China in the past three decades. We aim to quantify (1) changes of maize phenology and growth durations under the combined effects of climate change, cultivar shifts and sowing dates; (2) climate change during the observed maize growth period; (3) the impacts of climate change on maize yield at different production zones of China accounting for the adaptations (Fig. 1). We try to quantify climate impacts on crop growth and yield under the interactions between climate warming and crop system dynamics, instead of climate warming per se or climate warming impacts without adaptations.

\section{Materials and methods}

\subsection{Experimental stations and data}

Experimental observations data on maize cultivars, phenology, yields and management practices during 1981-2009 were from China agricultural meteorological experiment stations, which were maintained by China Meteorological Administration (CMA). There were total 167 geographically and climatologically different agricultural meteorological experiment stations across the major maize production regions (Fig. 1). Based on the maize cultivation zones in China (Tong, 1992), the agricultural meteorological stations were grouped into five zones, i.e., Zone I, Zone II, Zone III, Zone IV, and Zone V (Fig. 1). The information of the dominant cropping system, typical sowing date and maturity date at each zone was presented 
Table 1

The dominant cropping system, typical sowing date and maturity date at each maize production zone of China in the last years.

\begin{tabular}{|c|c|c|c|c|}
\hline Zones & Abbreviation & Dominant cropping system & Sowing date & Maturity date \\
\hline Zone I & Zone I_SP & Spring maize & April 20th & September 15 th \\
\hline Zone II & Zone II_SP & Spring maize or rice & April 30th & September 20th \\
\hline Zone III & Zone III_S & Rotation between summer maize and winter wheat & June 10th & September 20th \\
\hline \multirow[t]{2}{*}{ Zone IV } & Zone IV_SP & Spring maize & March 30th & August 1st \\
\hline & Zone IV_S & Rotation between spring cereals and summer maize & May 15th & September 10th \\
\hline \multirow[t]{2}{*}{ Zone V } & Zone V_SP & Spring maize & April 25th & September 20th \\
\hline & Zone V_S & Rotation between winter wheat and summer maize & June 30th & October 5 th \\
\hline
\end{tabular}

Table 2

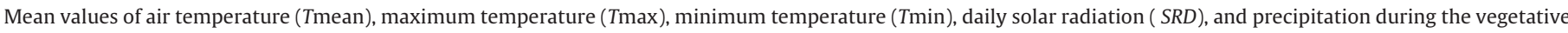

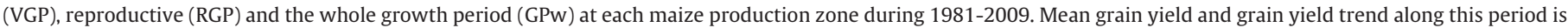
also included.

\begin{tabular}{|c|c|c|c|c|c|c|c|c|}
\hline Zone & Period & $\begin{array}{l}\text { Mean } \\
\text { Yield(kg/ha) }\end{array}$ & $\begin{array}{l}\text { Yield trend } \\
\text { (kg/ha/year) }\end{array}$ & $\begin{array}{l}\mathrm{T}_{\text {mean }} \\
\left({ }^{\circ} \mathrm{C}\right)\end{array}$ & $\begin{array}{l}\mathrm{T}_{\max } \\
\left({ }^{\circ} \mathrm{C}\right)\end{array}$ & $\begin{array}{l}\mathrm{T}_{\min } \\
\left({ }^{\circ} \mathrm{C}\right)\end{array}$ & $\begin{array}{l}\text { Precipitation } \\
(\mathrm{mm})\end{array}$ & $\begin{array}{l}\text { SRD } \\
\left(\mathrm{MJ} / \mathrm{m}^{2} / \text { day }\right)\end{array}$ \\
\hline \multirow[t]{3}{*}{ Zone I_SP } & VGP & & & 21.26 & 27.88 & 15.15 & 165.81 & 19.43 \\
\hline & RGP & & & 21.28 & 27.41 & 16.32 & 165.66 & 16.74 \\
\hline & GPw & 6242.13 & 125.56 & 21.22 & 27.63 & 15.60 & 328.68 & 18.26 \\
\hline Zone & VGP & & & 20.92 & 26.49 & 15.63 & 239.15 & 19.12 \\
\hline \multirow[t]{2}{*}{ II_SP } & RGP & & & 20.55 & 26.14 & 15.66 & 195.60 & 16.47 \\
\hline & GPw & 6420.10 & 164.38 & 20.70 & 26.29 & 15.58 & 430.02 & 17.94 \\
\hline Zone & VGP & & & 26.02 & 31.04 & 21.75 & 241.66 & 16.99 \\
\hline \multirow[t]{2}{*}{ III_S } & RGP & & & 23.56 & 28.65 & 19.48 & 150.48 & 15.17 \\
\hline & GPw & 5249.92 & 109.58 & 24.86 & 29.92 & 20.67 & 388.18 & 16.17 \\
\hline Zone & VGP & & & 21.23 & 25.93 & 17.83 & 342.24 & 12.07 \\
\hline \multirow[t]{2}{*}{ IV_SP } & RGP & & & 25.74 & 30.40 & 22.43 & 285.43 & 13.57 \\
\hline & GPw & 4818.59 & 12.74 & 22.86 & 27.54 & 19.49 & 624.08 & 12.61 \\
\hline Zone & VGP & & & 22.91 & 27.58 & 19.59 & 425.46 & 14.03 \\
\hline \multirow[t]{2}{*}{ IV_S } & RGP & & & 23.54 & 28.35 & 20.27 & 296.15 & 14.88 \\
\hline & GPw & 4349.41 & 85.19 & 23.13 & 27.85 & 19.83 & 715.22 & 14.33 \\
\hline Zone & VGP & & & 22.19 & 29.57 & 14.93 & 42.58 & 23.32 \\
\hline \multirow[t]{2}{*}{ V_SP } & RGP & & & 21.87 & 29.72 & 14.75 & 28.64 & 20.70 \\
\hline & GPw & 6931.92 & 243.07 & 22.02 & 29.61 & 14.82 & 70.71 & 22.19 \\
\hline Zone & VGP & & & 25.90 & 33.24 & 18.78 & 13.86 & 21.70 \\
\hline \multirow[t]{2}{*}{ V_S } & RGP & & & 20.43 & 28.50 & 12.95 & 6.39 & 18.24 \\
\hline & GPw & 3711.82 & 161.37 & 23.18 & 30.88 & 15.90 & 20.18 & 20.00 \\
\hline
\end{tabular}

in Table 1. The dominant cropping system in Zone I was spring maize (thereafter, Zone I_SP), in Zone II was spring maize (thereafter, Zone II_SP) or rice, in Zone III was rotation between summer maize (thereafter, Zone III_S) and winter wheat, in Zone IV was spring wheat (thereafter, Zone IV_SP) or rotation between spring cereals and summer maize (thereafter, Zone IV_S), in Zone V was spring maize (thereafter, Zone V_SP) or rotation between winter wheat and summer maize (thereafter, Zone V_S). The general information of maize yields and climate during growth period at each zone was presented in Table 2. There were 24, 50, 48, 11, 9, 18 and 7 agricultural meteorological experiment stations for Zone I_SP, Zone II_SP, Zone III_S, Zone IV_SP, Zone IV_S, Zone V_SP and Zone V_S, respectively.

Daily mean temperature ( $\left.T_{\text {mean }}\right)$, maximum temperature $\left(T_{\max }\right)$, minimum temperature $\left(T_{\min }\right)$, solar radiation $(S R D)$, precipitation and sunshine duration at the agricultural meteorological stations from 1981 to 2009 were also obtained from CMA. SRD was estimated using sunshine duration observation and the Angstrom-Prescott equation (Prescott, 1940) when SRD was not recorded. There was very few missing data in the daily weather data series, which were filled using the corresponding values at the nearest neighboring station.

\subsection{Methods}

Station-specific analyses showed that crop phenology and grain yields, as well as their responses to climate change, were relatively heterogeneous across the stations within a zone. Statistical models that relied on information from multiple stations, namely panel models, were documented to be better at predicting crop responses to temperature change than time-series statistical models at each station (Lobell and Burke, 2009). Therefore, the 24, 50, 48, 11, 9, 18 and 7 stations for Zone I_SP, Zone II_SP, Zone III_S, Zone IV_SP, Zone IV_S, Zone V_SP and Zone V_S were combined to conduct a panel analysis for each zone, respectively.

Across the stations for Zone I_SP, Zone II_SP, Zone III_S, Zone IV_SP, Zone IV_S, Zone V_SP and Zone V_S, respectively, time trends in sowing dates, anthesis dates, maturity dates (expressed in Julian days) and yields during 1981-2009 were analyzed using the linear regression method. Likewise, time trends in $T_{\operatorname{mean}}, T_{\max }, T_{\min }$, $S R D$ and precipitation during maize vegetative growth period (VGP, from sowing to anthesis), reproductive growth period (RGP, from anthesis to maturity), and whole growth period (GPw, from sowing to maturity) were analyzed. Seasonal mean $T_{\operatorname{mean}}, T_{\max }, T_{\min }$, $S R D$,precipitation and crop growing degree days (GDD) during VGP, RGP and GPw in each year at each station were computed based on the observed records of sowing, anthesis and maturity dates, which accelerated careful matching of weather variables with farm-specific planting and harvesting dates and crop-growth phases. By this way, the adaptation options such as the shifts of sowing, anthesis, maturity date, and cultivars were implicitly taken into account in the analyses. GDD during a growth period was calculated from hourly temperature obtained by fitting a sine curve to daily $T_{\max }$ and $T_{\min }$ as done in some previous studies (Jones et al., 
2003), with the cardinal base temperature, optimum temperature and maximum temperature of $8^{\circ} \mathrm{C}, 30^{\circ} \mathrm{C}$ and $34^{\circ} \mathrm{C}$, respectively.

To investigate the correlations between annual yields with climate variables during VGP, RGP and GPw across the stations for Zone I_SP, Zone II_SP, Zone III_S, Zone IV_SP, Zone IV_S, Zone V_SP and Zone V_S, respectively, the yields were firstly linearly de-trended to get the de-trended yield series that were mainly affected by seasonal climate variability. Then the climate variables were also linearly de-trended, and the partial correlation analysis was applied to investigate the correlation between the de-trended yields series (residuals) and the de-trended climate variables series (residuals) during 1981-2009. Statistical significance was tested using the two-tailed $t$-test.

There was no single regression model that performed best for all the zones. As in Tao et al. (2014a), to avoid the confounding effects of highly correlated climate variables, four panel regression models with different predictors were estimated for Zone I_SP, Zone II_SP, Zone III_S, Zone IV_SP, Zone IV_S, Zone V_SP and Zone V_S, respectively, to quantify the uncertainties in estimating yield sensitivity to each of three climate variable, i.e., $T_{\text {mean }}$, precipitation and $S R D$ (total seven panel regression models for each growth period at each zone). The Huber-White robust standard errors clustered by station were conducted, which showed the error term in the regression model was identically and independently distributed. For GPw, the seven panel regression models as follows were estimated:

$$
\begin{aligned}
& Y d_{i, t}=\beta_{i, 0}+\beta_{1} t+\beta_{2} \Delta T_{\text {meani,t }}+\epsilon_{i, t} \\
& Y d_{i, t}=\beta_{i, 0}+\beta_{1} t+\beta_{2} \Delta T_{\text {meani,t }}+\beta_{3} \Delta P_{i, t}+\epsilon_{i, t} \\
& Y d_{i, t}=\beta_{i, 0}+\beta_{1} t+\beta_{2} \Delta T_{\text {meani, },}+\beta_{4} \Delta S R D_{i, t}+\epsilon_{i, t} \\
& Y d_{i, t}=\beta_{i, 0}+\beta_{1} t+\beta_{2} \Delta T_{\text {meani,t }}+\beta_{3} \Delta P_{i, t}+\beta_{4} \Delta S R D_{i, t}+\epsilon_{i, t} \\
& Y d_{i, t}=\beta_{i, 0}+\beta_{1} t+\beta_{3} \Delta P_{i, t}+\epsilon_{i, t} \\
& Y d_{i, t}=\beta_{i, 0}+\beta_{1} t+\beta_{3} \Delta P_{i, t}+\beta_{4} \Delta S R D_{i, t}+\epsilon_{i, t} \\
& Y d_{i, t}=\beta_{i, 0}+\beta_{1} t+\beta_{4} \Delta S R D_{i, t}+\epsilon_{i, t}
\end{aligned}
$$

where $Y d_{i, t}$ is annual yield observations at station $i$ in year $t, \beta_{i, 0}$ represents an intercept, for each station $i$. $\beta_{1}$ represents the linear time trend of observed yields mainly due to the long-term climatic and no-climatic trends including improvements in varieties, technology, management and policy during the study period. $\beta_{1-4}$ are model parameters to be fit, and $\epsilon_{i, t}$ is an error term. $\Delta T_{\text {mean } i, t}$, $\Delta P_{i, t}$ and $\triangle S R D_{i, t}$ represents the linearly de-trended growing season average for $T_{\text {mean }}$, precipitation and $S R D$, respectively, at station $i$ in year $t$.

Among the seven panel regression models, Eqs. (1)-(4) were used to quantify yield sensitivity to $T_{\text {mean. }}$ Eqs. (5), (2), (6) and (4), were used to quantify yield sensitivity to precipitation. And Eqs. (7), (3), (6) and (4) were used to quantify yield sensitivity to SRD. The parameter $\beta_{2}$ represents yield sensitivity to $T_{\text {mean }}$ during GPw. Likewise, the parameter $\beta_{3}$ represents yield sensitivity to precipitation during $\mathrm{GPw}$. And the parameter $\beta_{4}$ represents yield sensitivity to SRD during GPw.

Likewise, for VGP and RGP together, total seven panel regression models as follows were estimated:

$$
\begin{aligned}
Y d_{i, t}= & \beta_{i, 0}+\beta_{1} t+\beta_{2} \Delta T_{\text {meani, }, \mathrm{VGP}}+\beta_{5} \Delta T_{\text {meani,t, } \mathrm{RGP}}+\epsilon_{i, t} \\
Y d_{i, t}= & \beta_{i, 0}+\beta_{1} t+\beta_{2} \Delta T_{\text {meani,t, } \mathrm{VGP}}+\beta_{3} \Delta P_{i, t, \mathrm{VGP}} \\
& +\beta_{5} \Delta T_{\text {meani, }, \mathrm{RGP}}+\beta_{6} \Delta P_{i, t, \mathrm{RGP}}+\epsilon_{i, t}
\end{aligned}
$$

$$
\begin{aligned}
Y d_{i, t}= & \beta_{i, 0}+\beta_{1} t+\beta_{2} \Delta T_{\text {meani,t, } \mathrm{VGP}}+\beta_{4} \Delta S R D_{i, t, \mathrm{VGP}} \\
& +\beta_{5} \Delta T_{\text {meani, }, \mathrm{RGP}}+\beta_{7} \Delta S R D_{i, t, \mathrm{RGP}}+\epsilon_{i, t}
\end{aligned}
$$

$$
\begin{aligned}
Y d_{i, t}= & \beta_{i, 0}+\beta_{1} t+\beta_{2} \Delta T_{\text {meani,t, } \mathrm{VGP}}+\beta_{3} \Delta P_{i, t, \mathrm{VGP}}+\beta_{4} \Delta S R D_{i, t, \mathrm{VGP}} \\
& +\beta_{5} \Delta T_{\text {mean } i, t, \mathrm{RGP}}+\beta_{6} \Delta P_{i, t, \mathrm{VGP}}+\beta_{7} \Delta S R D_{i, t, \mathrm{RGP}}+\epsilon_{i, t}(11)
\end{aligned}
$$

$Y d_{i, t}=\beta_{i, 0}+\beta_{1} t+\beta_{3} \Delta P_{i, t, \mathrm{VGP}}+\beta_{6} \Delta P_{i, t, \mathrm{VGP}}+\epsilon_{i, t}$

$Y d_{i, t}=\beta_{i, 0}+\beta_{1} t+\beta_{3} \Delta P_{i, t, \mathrm{VGP}}+\beta_{4} \Delta S R D_{i, t, \mathrm{VGP}}+\beta_{6} \Delta P_{i, t, \mathrm{VGP}}$

$+\beta_{7} \Delta S R D_{i, t, \mathrm{RGP}}+\epsilon_{i, t}$

$Y d_{i, t}=\beta_{i, 0}+\beta_{1} t+\beta_{4} \Delta S R D_{i, t, \mathrm{VGP}}+\beta_{7} \Delta S R D_{i, t, \mathrm{RGP}}+\epsilon_{i, t}$

where $Y d_{i, t}, \beta_{i, 0}$ and $\beta_{1}$ are the same as in Eq. (1); $\beta_{2-4}$ and $\beta_{5-7}$ are model parameters to be fit for VGP and RGP, respectively. $\Delta T_{\text {mean } i, t, \mathrm{VGP},} \Delta P_{i, t, \mathrm{VGP}}$ and $S R D_{i, t, \mathrm{VGP}}$ represents the linearly detrended growing season average for $T_{\text {mean }}$, precipitation and SRD during VGP, respectively, at station $i$ in year $t . \Delta T_{\text {mean } i, t, \mathrm{RGP},} \Delta P_{i, t, \mathrm{RGP}}$ and $S R D_{i, t, R G P}$ represents the linearly de-trended growing season average for $T_{\text {mean }}$, precipitation and SRD during RGP, respectively, at station $i$ in year $t$.

Among the seven models, Eqs. (8)-(11) were used to quantify yield sensitivity to $T_{\text {mean }}$. Eqs. (12), (9), (13) and (11) were used to quantify yield sensitivity to precipitation. And Eqs. (14), (10), (13) and (11) were used to quantify yield sensitivity to $S R D$. The parameters $\beta_{2}$ and $\beta_{5}$ represent yield sensitivity to $T_{\text {mean }}$ during VGP and RGP, respectively. The parameters $\beta_{3}$ and $\beta_{6}$ represent yield sensitivity to precipitation during VGP and RGP, respectively. The parameters $\beta_{4}$ and $\beta_{7}$ represent yield sensitivity to $S R D$ during VGP and RGP, respectively.

The Durbin-Watson statistic was conducted to test the null hypothesis that the residuals from an ordinary least-squares regression are not autocorrelated (Table S1). A set of model parameters for each panel model was estimated using multiple regression method, based on the field observations on yield and climate from 1981 to 2009, across all the stations for Zone I_SP, Zone II_SP, Zone III_S, Zone IV_SP, Zone IV_S, Zone V_SP and Zone V_S, respectively. The estimates of model parameters (i.e., $\beta_{1-7}$ ), expressed in percentage of average yield across these stations, represented the common sensitivity of yield change to $T_{\text {mean }}$, precipitation and SRD change, respectively, across these stations and during the growth period. The impact of change in a climate variable (i.e., $T_{\text {mean }}$, precipitation and SRD) on crop yields during 1981-2009 (expressed as a percentage of mean yield) was estimated by multiplying the sensitivity of yield change to the climate variable (expressed as a percentage of mean yield) with the magnitude of change in the climate variable across these stations during the study period. The later was estimated by a linear trend. The joint impacts of climate change on crop yields during 1981-2009 (expressed in percentage of mean yield) were computed by summing the impacts of changes in $T_{\text {mean }}$, precipitation and SRD on crop yields during the study period. The climate-related changes in the crop yield were compared with the actual mean yield across the stations during the study period.

\section{Results}

\subsection{Climate change during maize growth period in the past three} decades

During 1981-2009, climate change during maize growth period showed a spatially explicit pattern across the major maize production zones in China (Fig. 2). $T_{\text {mean }}$ increased significantly during 

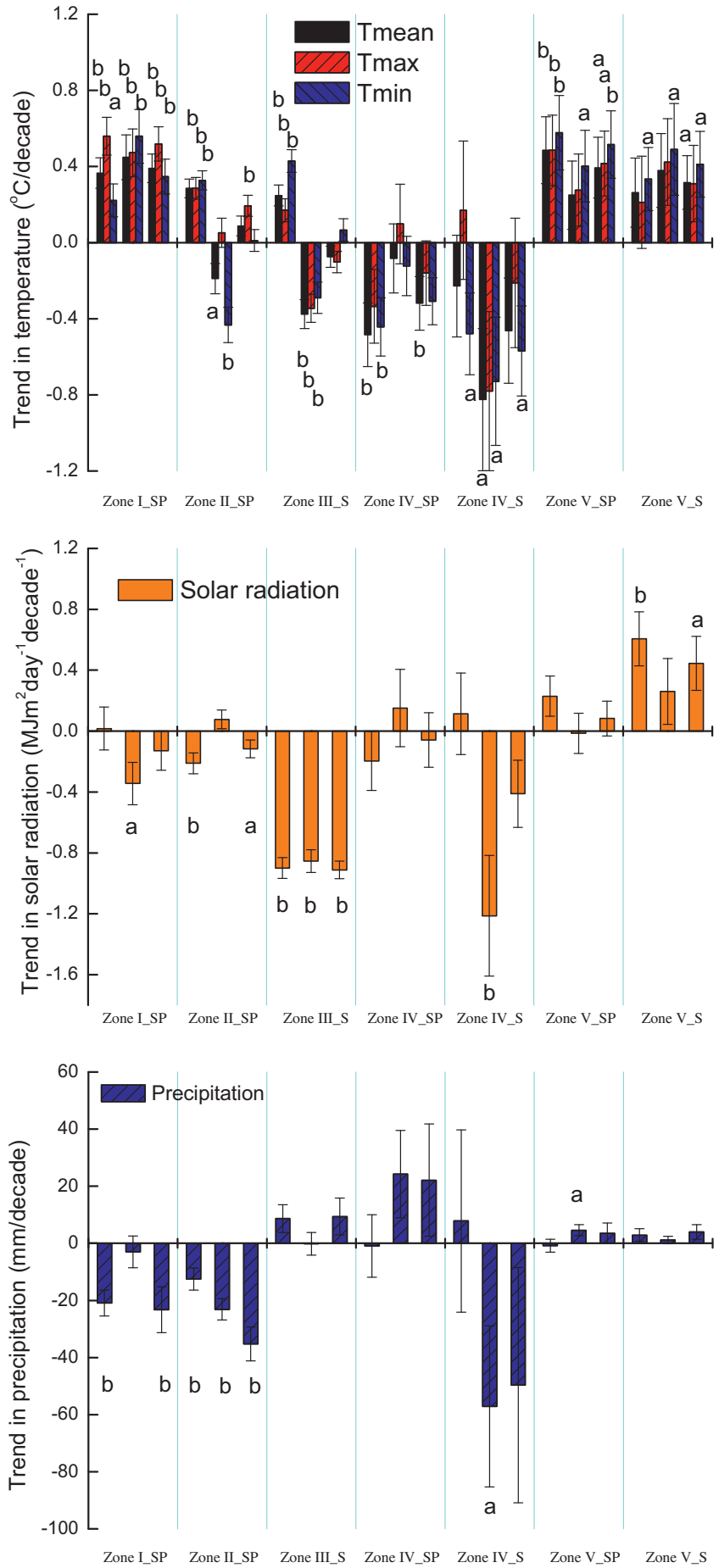

Fig. 2. Trends in mean temperature, solar radiation and precipitation during VGP (left), RGP (middle) and GPw (right) of maize during 1981-2009 at each maize production zone of China. The trends with a mark 'a' are significant at 0.05 level, and with a mark 'b' are significant at 0.01 level. The error bars represent the standard deviations of the means.

VGP, RGP and GPw for Zone I_SP, Zone V_SP and Zone V_S, and during VGP of Zone II_SP and Zone III_S. In contrast, it decreased significantly during RGP of Zone II_SP, Zone III_S, Zone IV_SP and Zone IV_S. Generally $T_{\max }$ and $T_{\min }$ had the same trends as $T_{\text {mean }}$ during each growth period at each zone. SRD decreased significantly during VGP, RGP and GPw of Zone III_S, during VGP of Zone II_SP, and during RGP of Zone I_SP and Zone IV_S. In contrast, it increased significantly during VGP and GPw of Zone V_S. Precipitation decreased significantly during GPw of Zone I_SP, Zone II_SP and Zone IV_S, in contrast increased significantly during GPw of Zone V_SP (Fig. 2).

\subsection{Changes in phenological dates and the durations of maize growth periods in relation to air temperature}

During 1981-2009, maize sowing date, anthesis date and maturity date were all significantly advanced for Zone I_SP, in contrast significantly delayed for Zone III_S (Table 3). Sowing date was significantly delayed, while anthesis date was significantly advanced for Zone V_SP. Duration of VGP was shortened significantly for Zone III_S, Zone IV_SP and Zone V_SP, in contrast duration of RGP was significantly prolonged for Zone II_SP, Zone III_S, and Zone V_SP. Finally, duration of GPw increased significantly for Zone II_SP, Zone III_S and Zone IV_S (Table 3). The GDD during VGP, RGP and GPw generally increased except for Zone IV_SP. Durations of VGP, RGP and GPw were negatively correlated to $T_{\text {mean }}$ in all the zones except the VGP and GPw of Zone IV_SP (Table 4).

\subsection{Correlations between changes in yields and climate during each growth period}

Yield was generally positively correlated to $T_{\text {mean }}$ in all the zones except Zone IV_SP and Zone V_SP, where yield was negatively correlated to $T_{\text {mean }}$ during RGP and VGP, respectively (Table 5). The correlations between yields and $T_{\max }$, as well as between yields and $T_{\text {min }}$, were generally same as those between yields and $T_{\text {mean }}$ at each zone. Yield was also significantly positively correlated to $S R D$ at all the zones except Zone I_SP and Zone II_SP(Table 5), where yield was significantly positively correlated to $T_{\text {mean }}$ and precipitation during RGP and GPw (Table 5).

\subsection{Sensitivity of yield change to climate variables during maize growth period}

The estimates on sensitivity of yield change to climate variables using four different models were generally comparable; suggesting the methods and estimates were generally sound (e.g., not affected much by the potential collinearity among climate variables). Yield response of spring maize crops to $T_{\text {mean }}$ and $S R D$ during VGP and RGP in Zone I_SP (Fig. 3a) was similar to those of Zone II_SP (Fig. 3b) and Zone V_SP (Fig. 3f). By contrast yield response to these meteorological conditions of Zone IV_SP (Fig. 3d) was opposite to those of mentioned zones. For summer maize crops such as those of Zone III_S (Fig. 3c), Zone IV_S (Fig. 3e) and Zone V_S (Fig. 3g), changes of climate variable during RGP had the highest impact of yield variations. Yield for Zone I_SP increased by $2.2 \%$ (2.0\%) for each $1{ }^{\circ} \mathrm{C}$ increase in $T_{\text {mean }}$, and by $1.0 \%$ (1.1\%) if precipitation increased by $10 \%$ during RGP (GPw) (Fig. 3a). Yield for Zone II_SP increased by $2.7 \%$ (3.1\%) for each $1{ }^{\circ} \mathrm{C}$ increase in Tmean during RGP (GPw) (Fig. 3b). For Zone III_S, yield was most sensitive to $T_{\text {mean }}$ and SRD during RGP (Fig. 3c), which increased by $2.0 \%$ (2.1\%) for each $1{ }^{\circ} \mathrm{C}$ increase in $T_{\text {mean }}$, and by $3.9 \%$ (4.2\%) if SRD increased by $10 \%$ during RGP (GPw) (Fig. 3c). For Zone IV_SP, yield increased by $0.9 \%$ for each $1{ }^{\circ} \mathrm{C}$ increase in $T_{\text {mean }}$, and by $4.6 \%$ if SRD increased by $10 \%$ during GPw; however decreased by $5.5 \%$ for each $1{ }^{\circ} \mathrm{C}$ increase in $T_{\text {mean }}$ during RGP (Fig. 3d). For Zone IV_S, yield increased by $1.6 \%(2.2 \%)$ for each $1{ }^{\circ} \mathrm{C}$ increase in $T_{\text {mean }}$, and by $6.4 \%$ (11.1\%) if SRD increased by $10 \%$ during RGP (GPw) (Fig. 3e). For Zone V_SP, yield increased by $4.1 \%$ (decreased by $2.1 \%$ ) for each $1{ }^{\circ} \mathrm{C}$ increase in $T_{\text {mean }}$, however increased by $11.9 \%$ (11.4\%) if SRD increased by $10 \%$ during RGP (GPw) (Fig. 3f). For Zone V_S, yield was most sensitive to $T_{\text {mean }}$ during RGP, which increased by $7.0 \%(7.4 \%)$ for each $1{ }^{\circ} \mathrm{C}$ increase in $T_{\text {mean }}$, and by $0.7 \%$ (9.8\%) if SRD increased by $10 \%$ during RGP (GPw) (Fig. 3g). 

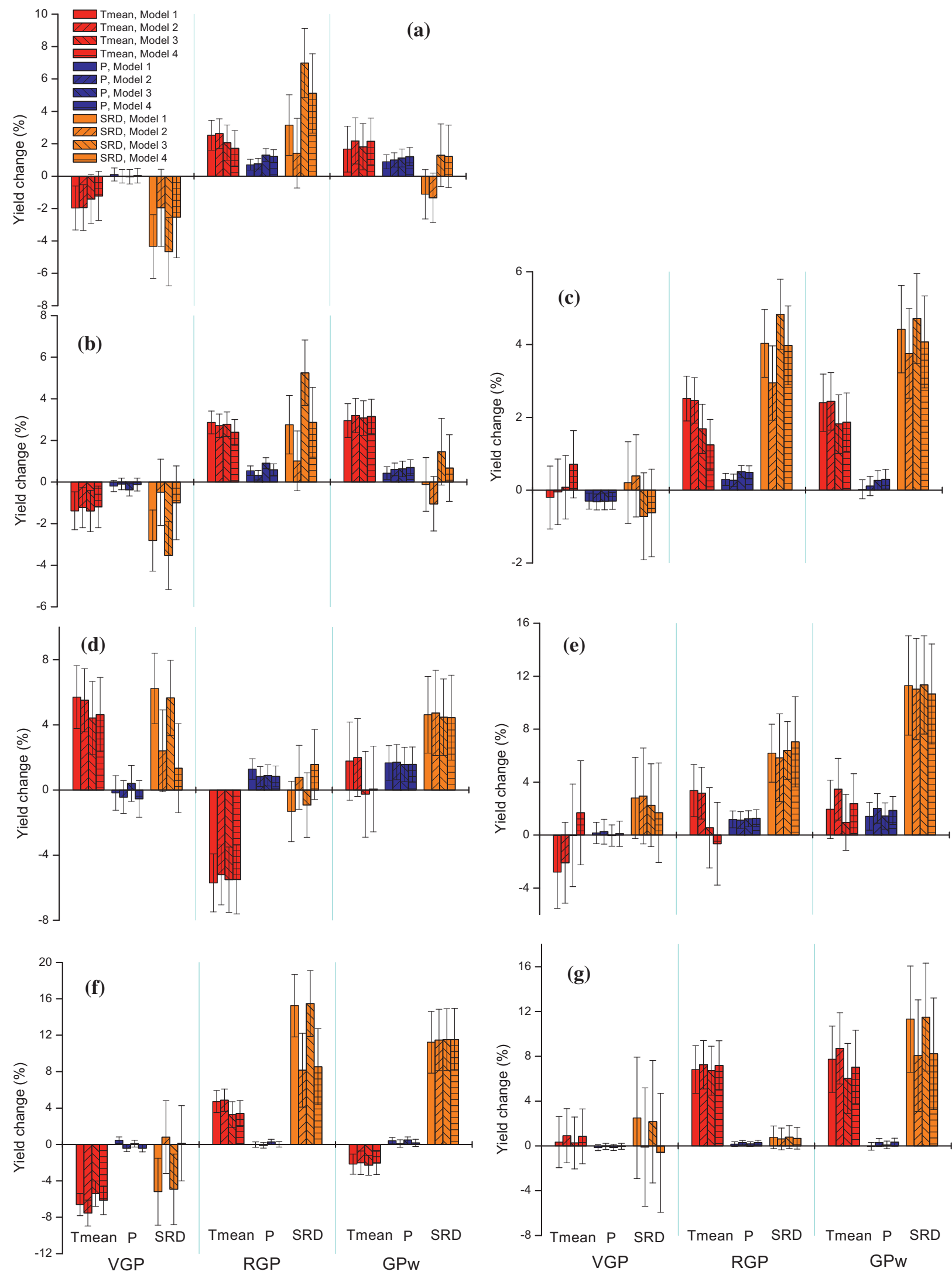

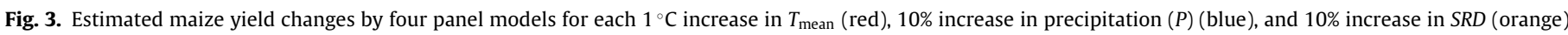

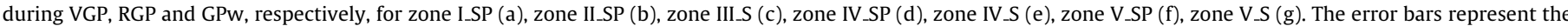
standard deviations of the means.(For interpretation of the references to color in this figure legend, the reader is referred to the web version of this article.) 
Table 3

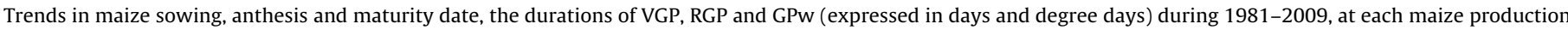
zone of China. The trends with '*' and '**' are significant at the 0.05 and 0.01 level, respectively.

\begin{tabular}{|c|c|c|c|c|c|c|c|}
\hline & Zone I_SP & Zone II_SP & Zone III_S & Zone IV_SP & Zone IV_S & Zone V_SP & Zone V_S \\
\hline Sowing date (days/decade) & $-1.73^{* *}$ & 0.16 & $2.12^{* *}$ & -0.20 & -1.72 & $1.92^{*}$ & -1.68 \\
\hline Anthesis date (days/decade) & $-1.53^{* *}$ & 0.24 & $1.30^{* *}$ & -2.59 & 1.93 & $-1.43^{*}$ & -1.07 \\
\hline Maturity date (days/decade) & $-1.81^{* *}$ & $3.58^{* *}$ & $3.92^{* *}$ & -1.81 & 4.48 & 0.58 & 0.29 \\
\hline VGP duration (days/decade) & 0.20 & 0.08 & $-0.82^{* *}$ & $-2.40^{*}$ & $3.64^{* *}$ & $-3.35^{* *}$ & 0.62 \\
\hline RGP duration (days/decade) & -0.28 & $3.34^{* *}$ & $2.63^{* *}$ & 0.79 & 2.55 & $2.01^{* *}$ & 1.35 \\
\hline GPw duration (days/decade) & -0.08 & $3.42^{* *}$ & $1.80^{* *}$ & -1.61 & $6.19^{* *}$ & -1.35 & 1.97 \\
\hline VGP_GDD (degree days/decade) & $22.12^{* *}$ & $21.81^{* *}$ & $5.94^{*}$ & -22.18 & $26.55^{*}$ & 6.04 & $25.49^{* *}$ \\
\hline RGP_GDD(degree days/decade) & $18.10^{* *}$ & $15.66^{* *}$ & $13.66^{* *}$ & 8.48 & -0.23 & $27.86^{* *}$ & $21.17^{* *}$ \\
\hline GPw_GDD(degree days/decade) & $39.88^{* *}$ & $37.46^{* *}$ & $19.56^{* *}$ & -13.39 & $26.56^{*}$ & $33.80^{* *}$ & $46.57^{* *}$ \\
\hline
\end{tabular}

Table 4

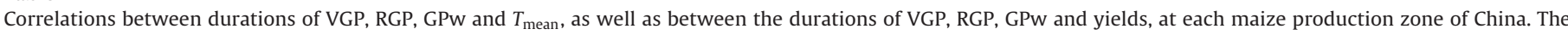
correlations with '*' and '**' are significant at the 0.05 and 0.01 level, respectively.

\begin{tabular}{|c|c|c|c|c|c|c|c|}
\hline & Zone I_SP & Zone II_SP & Zone III_S & Zone IV_SP & Zone IV_S & Zone V_SP & Zone V_S \\
\hline Duration of VGP \& $T_{\text {mean }}$ & $-0.32^{* *}$ & $-0.22^{* *}$ & $-0.37^{* *}$ & 0.13 & $-0.44^{* *}$ & $-0.57^{* *}$ & $-0.21^{*}$ \\
\hline Duration of RGP \& $T_{\text {mean }}$ & $-0.41^{* *}$ & $-0.37^{* *}$ & $-0.44^{* *}$ & $-0.39^{* *}$ & $-0.71^{* *}$ & $-0.32^{* *}$ & $-0.47^{* *}$ \\
\hline Duration of GPw \& $T_{\text {mean }}$ & $-0.41^{* *}$ & $-0.28^{* *}$ & $-0.41^{* *}$ & 0.10 & $-0.77^{* *}$ & $-0.67^{* *}$ & $-0.34^{* *}$ \\
\hline Duration of VGP \& yield & $-0.14^{* *}$ & 0.01 & $-0.12^{* *}$ & $0.29 * *$ & 0.02 & $-0.16^{* *}$ & -0.04 \\
\hline Duration of RGP \& yield & 0.05 & $0.25^{* *}$ & $0.26^{* *}$ & $0.37^{* *}$ & 0.19 & $0.27^{* *}$ & 0.08 \\
\hline Duration of GPw \& yield & -0.07 & $0.17^{* *}$ & $0.08^{*}$ & $0.41^{* *}$ & 0.14 & 0.00 & 0.03 \\
\hline
\end{tabular}

\subsection{Impacts of climate change over maize growth period on} yields during 1981-2009

Climate change over maize growth period during 1981-2009 had caused measurable impacts on maize yields. For Zone I_SP, increase in $T_{\text {mean }}$ had negative impacts on yields during VGP but had positive impacts during RGP (Fig. 4a). Decreases in SRD and precipitation had negative effects on yield formation during RGP. Yields increased by $2.5 \%$ due to increase in $T_{\text {mean }}$, however decreased by $2.5 \%$ due to decrease in precipitation, during GPw. For Zone II_SP, yields decreased due to decreases in $T_{\text {mean }}$ and precipitation during RGP, however increased due to increase in SRD (Fig. 4b). Finally changes in $T_{\text {mean }}$, precipitation and $S R D$ jointly had only small impacts on maize yields for Zone I_SP and Zone II_SP during 1981-2009 (Fig. 5).

For Zone III_S, decreases in $T_{\text {mean }}$ and SRD during RGP reduced yields by $2.5 \%$ and $7 \%$, respectively (Fig. $4 \mathrm{c}$ ). Decreases in $T_{\text {mean }}$ and $S R D$, and small change in precipitation, during RGP, jointly reduced maize yields by $8 \%$ (Fig. 5 ).

For Zone IV_SP, decreases in $T_{\text {mean }}$ and SRD had negative impacts on yields during VGP and GPw, however increase in precipitation had slight positive impacts during RGP and GPw (Fig. 4d). Decreases in $T_{\text {mean }}$ and $S R D$, together with increase in precipitation, jointly had negative impacts on yields during VGP, positive impacts during RGP, and eventually the impacts were almost balanced out during GPw (Fig. 5). For Zone IV_S, decreases in $T_{\text {mean }}$, precipitation and $S R D$ during RGP reduced yields by $7 \%, 6 \%$ and $15 \%$, respectively (Fig. 4e). Decreases in $T_{\text {mean }}$, precipitation and SRD jointly reduced yields by $25 \%$ and $15 \%$ during RGP and GPw, respectively (Fig. 5).

For Zone V_SP, increase in $T_{\text {mean }}$ had negative impacts on yields during VGP; however had positive impacts during RGP. Yield decreased by $2 \%$ due to increase in $T_{\text {mean }}$, however increased slightly due to increases in precipitation and $S R D$ during GPw (Fig. 4f). Increases in $T_{\text {mean }}$, precipitation and $S R D$ jointly had negative impacts on yields during VGP, positive impacts during RGP, and the impacts were eventually balanced out during GPw (Fig. 5). For Zone V_S, increases in $T_{\text {mean }}$ and SRD during GPw increased yields by $7 \%$ and $7 \%$, respectively (Fig. $4 \mathrm{~g}$ ). Increases in $T_{\text {mean }}$, precipitation and SRD jointly increased yields by $9 \%$ and $15 \%$ during RGP and GPw, respectively (Fig. 5).

Table 5

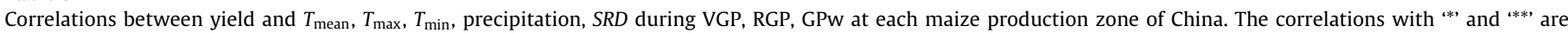
significant at the 0.05 and 0.01 level, respectively.

\begin{tabular}{|c|c|c|c|c|c|c|c|c|}
\hline Growing period & climate variables & Zone I_SP & Zone II_SP & Zone III_S & Zone IV_SP & Zone IV_S & Zone V_SP & Zone V_S \\
\hline \multirow[t]{5}{*}{ VGP } & $T_{\text {mean }}$ & -0.042 & 0.004 & 0.050 & $0.216^{* *}$ & -0.007 & $-0.222^{* *}$ & 0.046 \\
\hline & $T_{\max }$ & -0.042 & 0.043 & 0.035 & $0.202^{*}$ & -0.047 & $-0.225^{* *}$ & 0.053 \\
\hline & $T_{\min }$ & -0.065 & -0.012 & 0.022 & $0.222^{*}$ & 0.060 & $-0.231^{* *}$ & 0.077 \\
\hline & Precipitation & 0.046 & -0.003 & -0.041 & 0.002 & 0.016 & 0.084 & -0.066 \\
\hline & $S R D$ & -0.067 & -0.031 & 0.055 & $0.247^{* *}$ & 0.089 & 0.109 & 0.059 \\
\hline \multirow[t]{5}{*}{ RGP } & $T_{\text {mean }}$ & $0.124^{*}$ & $0.150^{* *}$ & $0.146^{* *}$ & $-0.241^{* *}$ & 0.164 & 0.043 & $0.306^{* *}$ \\
\hline & $T_{\max }$ & $0.100^{*}$ & $0.159^{* *}$ & $0.138^{* *}$ & $-0.193^{*}$ & 0.133 & 0.023 & $0.273^{* *}$ \\
\hline & $T_{\min }$ & $0.115^{*}$ & $0.145^{* *}$ & $0.121^{* *}$ & $-0.262^{* *}$ & 0.187 & -0.023 & $0.250^{* *}$ \\
\hline & Precipitation & $0.115^{*}$ & $0.067^{*}$ & 0.056 & $0.183^{*}$ & 0.222 & 0.037 & 0.064 \\
\hline & $S R D$ & 0.025 & 0.030 & $0.155^{* *}$ & 0.017 & $0.320^{* *}$ & $0.274^{* *}$ & 0.110 \\
\hline \multirow[t]{5}{*}{ GPw } & $T_{\text {mean }}$ & 0.060 & $0.109^{* *}$ & $0.103^{* *}$ & 0.067 & 0.106 & -0.120 & $0.253^{* *}$ \\
\hline & $T_{\max }$ & 0.033 & $0.125^{* *}$ & $0.091^{* *}$ & 0.074 & 0.059 & $-0.128^{*}$ & $0.198^{*}$ \\
\hline & $T_{\min }$ & 0.046 & $0.100^{* *}$ & $0.072^{*}$ & 0.076 & 0.157 & $-0.158^{*}$ & $0.218^{*}$ \\
\hline & Precipitation & $0.103^{*}$ & 0.042 & 0.003 & 0.140 & $0.343^{* *}$ & 0.073 & -0.023 \\
\hline & $S R D$ & -0.037 & -0.005 & $0.124^{* *}$ & 0.176 & 0.208 & $0.200^{* *}$ & $0.226^{*}$ \\
\hline
\end{tabular}



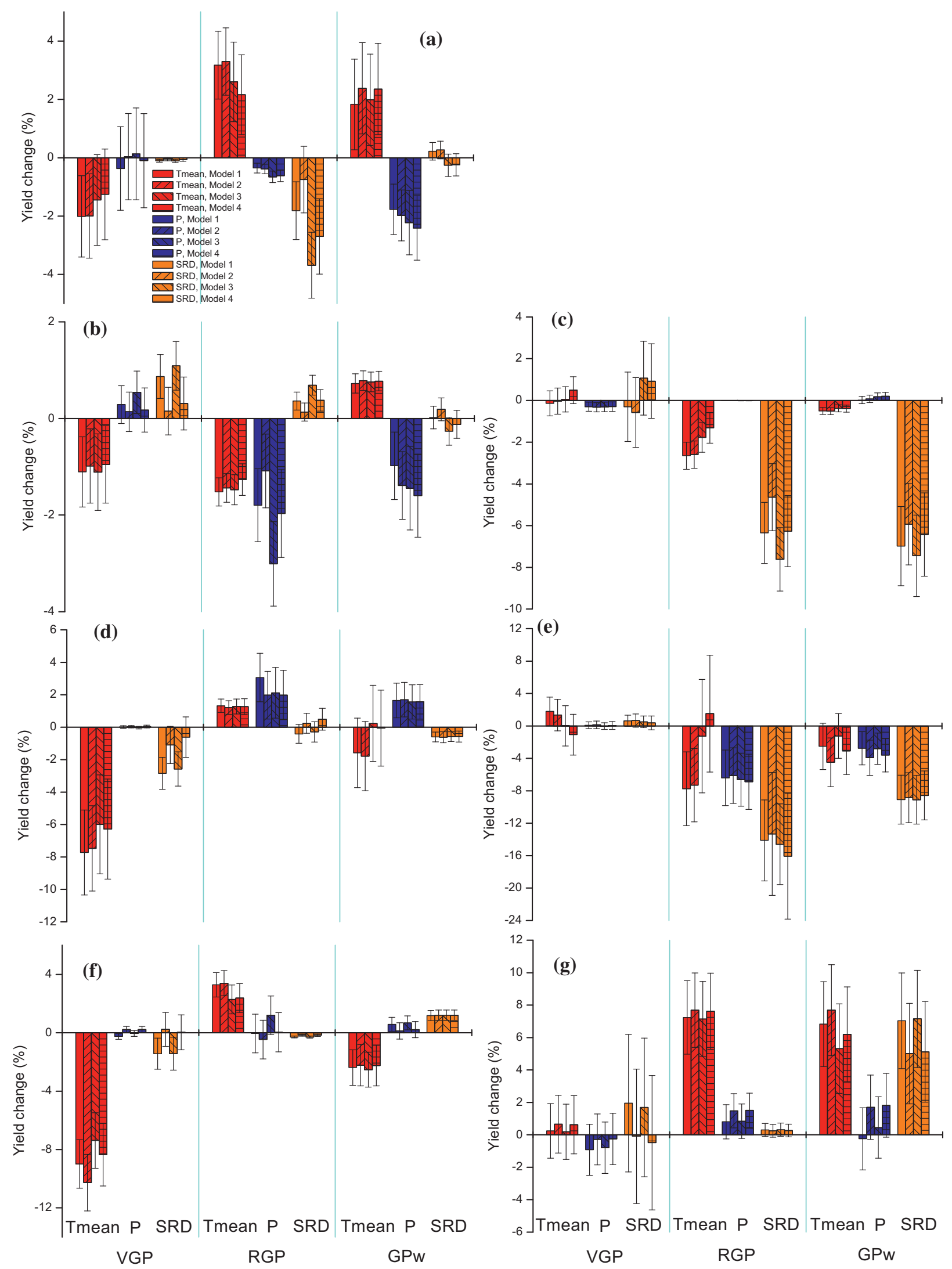

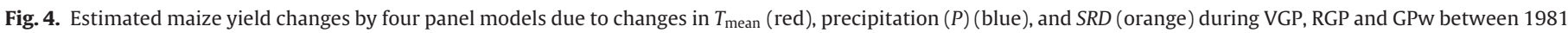

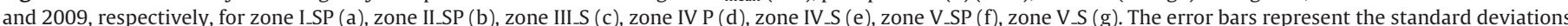
of the means. (For interpretation of the references to color in this figure legend, the reader is referred to the web version of this article.) 


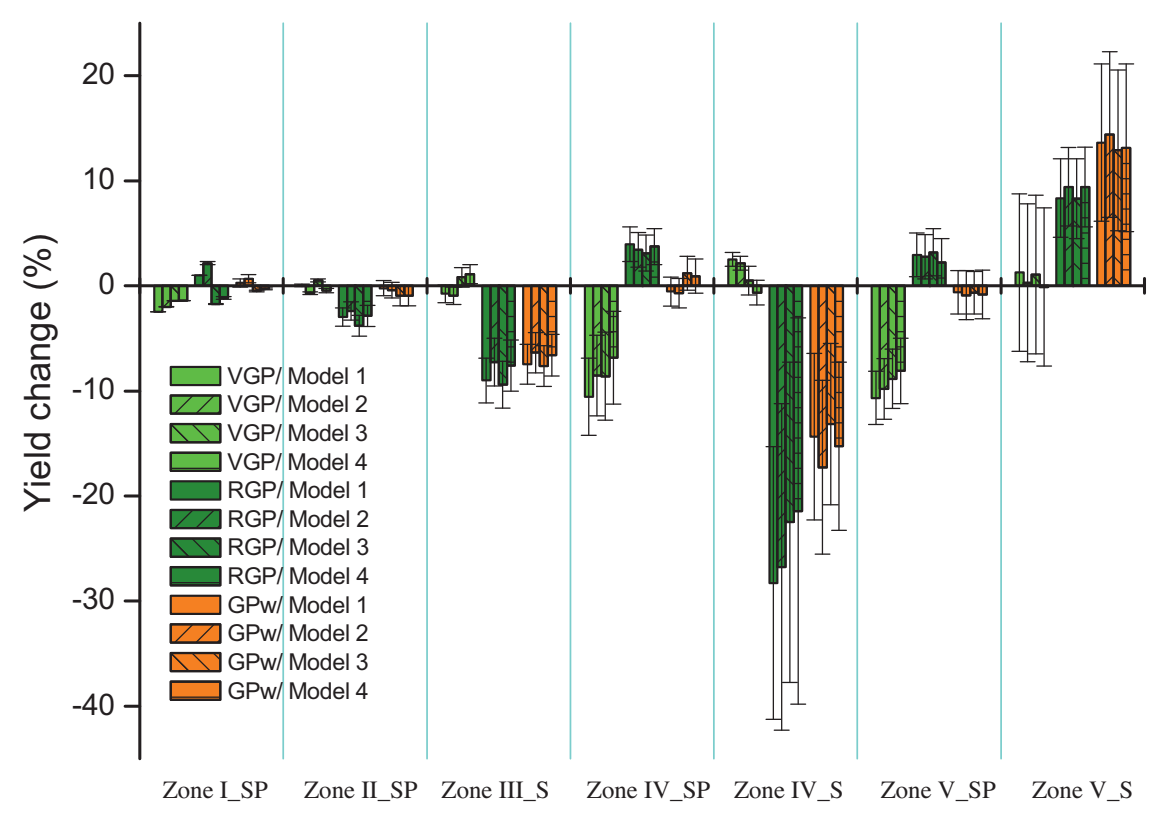

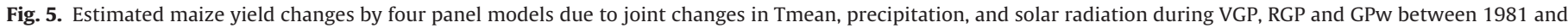
2009, respectively, at each maize production zone of China. The error bars represent the standard deviations of the means.

\section{Discussions}

\subsection{Spatial patterns of climate impacts on maize yield during 1981-2009}

Mean temperature during maize growth period in the major maize production regions of China generally lies within the optimum temperature range $\left(18-25^{\circ} \mathrm{C}\right.$; Muchow et al., 1990) for maize growth and yield (Table 2 ). Hence maize yields were generally positively correlated to Tmean in most of these zones, as was observed for maize regions of US (Schlenker and Roberts, 2009). Nevertheless, temperature was above the optimum range in some zones. For example, $T_{\text {mean }}$ and $T_{\max }$ during RGP of Zone IV_SP were $25.74{ }^{\circ} \mathrm{C}$ and $30.40^{\circ} \mathrm{C}$, respectively, above the optimum temperature range for reproductive yield. High temperature and drought stress during RGP were the major challenges for maize productivity for Zone IV_SP (Hu, 1993), hence maize yield was negatively correlated to $T_{\text {mean }}$ and $T_{\max }$. Due to advancement of phenological dates for Zone IV_SP (Table 3), Tmean during RGP decreased during 1981-2009 (Fig. 2), which reduced the negative impacts of temperature to some extent. In addition, the negative correlation between maize yield and temperature during VGP of Zone V_SP can be ascribed to increasing temperature-induced drought stress, considered that the little precipitation and the positive correlation between yield and precipitation in the zone.

The impacts of climate change on maize yields in China showed a spatially explicit pattern. The yields of Zone IV_S and Zone III_S were most negatively affected due to the significant decreasing trends in $T_{\text {mean }}$ and $S R D$ during growth period. By contrast, the yields of Zone V_S were most positively affected because of maturity date changed little and both Tmean and SRD during growth period had increased during 1981-2009. The Zone I_SP experienced the highest increase in temperature and less human intervention, as a result, maize sowing dates, anthesis dates and maturity dates of Zone I_SP were most affected by climate change. In comparisons with spring maize, changes of climate variable during RGP had the highest impact of yield variations for summer maize. This was because summer maize usually had shorter growing durations and later maturity dates than spring maize, and the climate during the RGP of summer maize was crucial however subjected to high variability and frost risk (Zhang et al., 2014).
Differences with previous studies of grain yield response to climatic trends (Lobell et al., 2011a; Tao et al., 2012) could be based on the temporal frame used at each study. In this work changes of sowing date and cultivar along time modified not only the length of growing season, but also the period occupied by maize crops along a year.

\subsection{Yield change due to genetic and agronomic management improvements}

In the past three decades, maize cultivars were shifted frequently, which contributed notably to yield increase, together with improvement of agronomic management practices (Ci et al., 2011; Chen et al., 2013). Recent genetic improvements in grain yield were primarily due to increased stress tolerance of new hybrids, as well as increased efficiency in grain production by maize plants (Ci et al., 2011). An field experimental study showed that the genetic gain in maize yield in China from 1970 s to 2000 s averaged $94.7 \mathrm{~kg} \mathrm{ha}^{-1}$ per year and 53\% of this was attributable to breeding (Ci et al., 2011), and the modern hybrids showed increased tolerance to multiple stresses. Another study showed the potential yield of individual hybrids increased by $118.5 \mathrm{~kg} \mathrm{ha}^{-1}$ per year with increasing year of release in northeastern China from 1973 to 2000 (Chen et al., 2013). Modern breeding increased ear fertility and grain-filling rate, and delayed leaf senescence without modification in net photosynthetic rate. Recently, Liu et al. (2013) indicated that earlier sowing dates and introduction of cultivars with higher thermal time requirements in northeastern China had overcome the negative effects of climate change during 1981-2007, through a crop model analyses. These results support our findings that observed yield trend ranged from $12.74 \mathrm{~kg} \mathrm{ha}^{-1}(0.26 \%)$ to $243.07 \mathrm{~kg} \mathrm{ha}^{-1}$ (4.3\%) per year, with an average of $128.84 \mathrm{~kg} \mathrm{ha}^{-1}(2.4 \%)$ per year, mainly due to cultivars turnover and advance in agronomic management (Table 3).

\subsection{Implications for adaptation of maize production to climate change}

Maize maturity was delayed, GDD of cultivars increased and durations of RGP and GPw were prolonged mainly due to cultivars turnover (Tao et al., 2014b; Xiao et al., 2015), particularly for Zone 
II_SP and Zone III_S. Decrease in $T_{\text {mean }}$ during growth period can further extend the duration of RGP to some extent (Fig. 2, Table 4). The duration of RGP was positively related to yield in all the maize cultivation zones, although the duration of VGP was negatively related to yield for Zone I_SP, Zone III_S and Zone V_SP (Table 4). Our results suggest that the late maturing cultivars with higher GDD and longer RGP duration were increasingly adopted to take advantage of increasing photo-thermal resource from climate change, which indeed boosted yield substantially in the past three decades, particularly for Zone II_SP and Zone III_S. The findings are supported by field experiments, which showed grain weight and yield increased by more than $10 \%$ if maturity dates were extended by $8-10$ days (Li et al., 2008; Lu et al., 2011) because a higher biomass accumulated during the effective grain filling period lead to larger kernel weights and yield. In addition, the delay of anthesis date and maturity date can also reduce the risk of extreme high temperature stress. However, the trade-off associated with delay in maturity was that $T_{\text {mean }}$ had a decreasing trend during RGP during 1981-2009, which reduced photosynthesis rate and had a negative impact on yield, particularly for Zone II_SP, Zone III_S and Zone IV_S; and even increased frost risk during RGP for Zone II_SP (Zhang et al., 2014).

The potential yields can be further promoted by selecting suitable sowing date and cultivars to avoid the negative impacts of climate change. For Zone I_SP, yield was negatively correlated to duration of VGP and positively correlated to duration of RGP (Table 4). However duration of VGP was slightly prolonged and duration of RGP was slightly shortened during 1981-2009 partly due to advancement of sowing date and maturity date (Table 3 ). Therefore, late maturing cultivars with longer growth period, together with late sowing, should be adopted in the zone so that duration of VGP can become shorter and duration of RGP can become longer. For Zone IV_SP, yield was significantly positively correlated to duration of RGP (Table 4), and duration of RGP was prolonged insignificantly during 1981-2009 (Table 3), therefore, late maturing cultivars with longer growth period, together with late sowing, should be adopted in the zone to extend duration of RGP further. For Zone V_SP, yield was negatively correlated to duration of VGP and positively correlated to duration of RGP (Table 4). During 1981-2009, duration of VGP was indeed shortened and RGP was indeed prolonged due to delay of sowing date and maturity date, as well as advancement of anthesis date (Table 3). Early sowing can be an effective adaptation option to reduce the negative impacts of climate warming during VGP. For Zone IV_S and Zone V_S, phenology date was not significantly shifted and yield was not significantly correlated with duration of growth period (Table 4), although duration of growth period was prolonged (Table 3). Climate had relatively large positive impacts on yields in Zone V.S, however, had relatively large negative impacts on yields in Zone IV_S (Fig. 5). To reduce the negative impacts of decreases in $T_{\text {mean }}$ and $S R D$, early maturing cultivars with medium growth period, as well as early sowing, should be adopted for Zone IV_S.

The findings have important implications not only for Chinese crop production but also for global crop production to adapt to future climate change. The insights gained from historical data suggest that adaptations of crop production to climate change through shifts of genotype and cropping system optimization will have large potentials to cope with climate risk in future. The historical experiences can be further combined with model-based studies to develop future climate change adaptation strategies through designing crop ideotype and climate-resilient cropping system (Rötter et al., 2015). Some model-based assessments have been conducted in recent years together with long-term historical trial data (e.g., Tao and Zhang, 2010; Martín et al., 2014; Xiao and Tao, 2014). These studies point towards need for cultivars with longer reproductive phases and higher thermal requirements under future climate scenarios in many regions. These studies also indicate that cropping system can be optimized to prevent anthesis stage from heat and drought stress and to make full use of improved photothermal resource under climate change conditions.

\section{Conclusions}

The detailed field observations at 167 agricultural meteorological stations across China spanning from 1981 to 2009 were used to investigate the response and adaptation of maize production to climate change in the past three decades. We found that once the crop systems dynamics were taken into account, solar radiation and temperature had decreasing trend during the period, and maize yields were positively correlated with solar radiation and temperature in major production regions. The decreases in solar radiation and temperature during growth period were mainly ascribed to adoption of late maturing cultivars with higher thermal requirements and longer RGP duration, which contributed substantially to yield increase. The historical experiences in the past three decades reveal insights into response and adaptation of maize growth and yield to climate change at different climate zones regions of China. Our findings highlight that the shifts between early and late maturity cultivars and sowing dates have mitigated the impact of climate change during the last three decades. These strategies could be further developed for future agricultural adaptation to climate change through designing crop ideotype and climate-resilient cropping system.

\section{Acknowledgements}

This study was supported by the National Science Foundation of China (Nos. 41571088, 41571493 and 31561143003 ). Funding support by FACCE MACSUR project through the Finnish Ministry of Agriculture and Forestry and by Luke through the strategic MODAGS project is also gratefully acknowledged. We are grateful to the two anonymous reviewers and editor for their insightful comments on an earlier version of this manuscript.

\section{Appendix A. Supplementary data}

Supplementary data associated with this article can be found, in the online version, at http://dx.doi.org/10.1016/j.fcr.2015.10.013.

\section{References}

Asseng, S., Ewert, F., Rosenzweig, C., Jones, J.W., Hatfield, J.L., et al., 2013. Quantifying uncertainties in simulating wheat yields under climate change. Nature Clim. Change 3, 827-832.

Bassu, S., Brisson, N., Durand, J., Boote, K., et al., 2014. How do various maize crop models vary in their responses to climate change factors? Glob. Change Biol. 20, 2301-2320.

Battisti, D.S., Naylor, R.L., 2009. Historical warnings of future food insecurity with unprecedented seasonal heat. Science 323, 240-244.

Bolanos, J., Edmeades, G.O., 1996. The importance of the anthesis-silking interval in breeding for drought tolerance in tropical maize. Field Crops Res. 48, 65-80.

Butler, E., Huybers, P., 2013. Adaptation of US maize to temperature variations. Nature Clim. Change 3, 68-72.

Cairns, J.E., Sonder, K., Zaidi, P.H., Verhulst, N., Mahuku, G., Babu, R., Nair, S.K., et al., 2012. Chapter one-maize production in a changing climate: impacts, adaptation, and mitigation strategies, In: Donald L. Sparks (Eds.), Advances in Agronomy, vol. 114, 1-58.

Cassman, K.G., 2007. Climate change, biofuels, and global food security. Environ. Res. Lett. 2, 011002.

Challinor, A., Wheeler, T., Garforth, C., Craufurd, P., Kassam, A., 2007. Assessing the vulnerability of food crop systems in Africa to climate change. Clim. Change 83, 381-399.

Chen, X., Chen, F., Chen, Y., Gao, Q., Yang, X., Yuan, L., Zhang, F., Mi, G., 2013. Modern maize hybrids in Northeast China exhibit increased yield potential and resource use efficiency despite adverse climate change. Glob. Change Biol. 19, 923-936.

Ci, X.K., Li, M.S., Liang, X.L., Xie, Z., Zhang, D., Li, X., Lu, Z., Ru, G., Bai, L., Xie, C., Hao, Z., Zhang, S., 2011. Genetic contribution to advanced yield for maize hybrids released from 1970 to 2000 in China. Crop Sci. 51, 1-8. 
Crafts-Brandner, S.J., Salvucci, M.E., 2002. Sensitivity of photosynthesis in a C4 plant, maize, to heat stress. Plant Physiol. 129, 1773-1780.

Elsgaard, L., Børgesen, C.D., Olesen, J.E., Siebert, S., Ewert, F., Peltonen-Sainio, P., Rötter, R.P., Skjelvåg, A.O., 2012. Shifts in comparative advantages for maize, oat and wheat cropping under climate change in Europe. Food Addit. Contam. Part A 29, 1514-1526.

FAO, 2012. Food and Agriculture Organization of the United Nations (FAO), FAO Statistical Databases; available at http://faostat.fao.org.

Godfray, C.H.J., John, R.B., Ian, R.C., Lawrence, H., David, L., James, F.M., Jules, P., Sherman, R., Sandy, M.T., Camilla, T., 2010. Food security: the challenge of feeding 9 billion people. Science 327, 812-818.

Hu, X.A., 1993. High yield cultivating techniques for spring maize in the hot and summer drought areas of southeast Sichuan. Southwest China. J. Agric. Sci. 6 $36-41$

IPCC, 2014. Climate Change 2014: Impacts, Adaptation, and Vulnerability. Part A: Global and Sectoral Aspects. Contribution of Working Group II to the Fifth Assessment Report of the Intergovernmental Panel on Climate Change. Cambridge University Press, Cambridge, United Kingdom and New York, NY, USA, 1132 pp.

Jones, J.W., Hoogenboom, G., Porter, C.H., Boote, K.J., Batchelor, W.D., Hunt, L.A., Wilkens, P.W., Singh, U., Gijsman, A.J., Ritchie, J.T., 2003. The DSSAT cropping system model. Eur. J. Agron. 18, 235-265.

Li, H., Bai, H., Wang, X., Meng, S., Wang, L., Zhang, J., 2008. Experiments on impacts of different harvest dates on summer maize yield. Bull. Agric. Sci. Technol. 6 , $80-82$

Lobell, D.B., Burke, M.B., 2009. On the use of statistical models to predict crop yield responses to climate change. Agric. For. Meteorol. 150, 1443-1452.

Lobell, D.B., Schlenker, W.S., Costa-Roberts, J., 2011a. Climate trends and global crop production since 1980 . Science 333, 616-620.

Lobell, D.B., Banziger, M., Magorokosho, C., Vivek, B., 2011b. Nonlinear heat effects on African maize as evidenced by historical yield trials. Nature Clim. Change 1 $42-45$

Lobell, D.B., Hammer, G.L., McLean, G., Messina, C., Roberts, M.J., Schlenker, W. 2013. The critical role of extreme heat for maize production in the United States. Nature Clim. Change 3, 497-501.

Liu, Z., Hubbard, K.G., Lin, X., Yang, X., 2013. Negative effects of climate warming on maize yield are reversed by the changing of sowing date and cultivar selection in Northeast China. Glob. Change Biol., http://dx.doi.org/10.1111/gcb.12324.

Lu, H., Xue, J., Ma, G., Zhang, R., Zhang, X., Li, F., Hao, Y., 2011. Effects of delaying harvest and different cultivation measures on yield and grain weight of maize. J. Maize Sci. 1, 101-104.

Martín, M.M., Olesen, J.E., Porter, J.R., 2014. A genotype, environment and management $(\mathrm{G} \times \mathrm{E} \times \mathrm{M})$ analysis of adaptation in winter wheat to climate change in Denmark. Agric. For. Meteorol. 187, 1-13.

Muchow, R.C., Sinclair, T.R., Bennett, J.M., 1990. Temperature and solar radiation effects on potential maize yield across locations. Agron. J. 82, 338-343.

Licker, R., Kucharik, C.J., Doré, T., Lindeman, M.J., Makowski, D., 2013. Climatic impacts on winter wheat yields in Picardy, France and Rostov, Russia: 1973-2010. Agric. For. Meteorol. 176, 25-37.

Olesen, J.E., Trnka, M., Kersebaum, K.C., Skjelvåg, A.O., Seguin, B., Peltonen-Sainio, P., Rossi, F., Kozyra, J., Micale, F., 2011. Impacts and adaptation of European crop production systems to climate change. Eur. J. Agron. 34, 96-112.

Prescott, J.A., 1940. Evaporation from a water surface in relation to solar radiation. T. R. Soc. S. Aust. 64, 114-115.

Rattalino Edreira, J.I., Budakli Carpici, E., Sammarro, D., Otegui, M.E., 2011. Heat stress effects around flowering on kernel set of temperate and tropical maize hybrids. Field Crops Res. 123, 62-73.

Rötter, R.P., Carter, T.R., Olesen, J.E., Porter, J.R., 2011. Crop-climate models need an overhaul. Nature Clim. Change 1,175-177.
Rötter, R.P., Tao, F., Höhn, J.G., Palosuo, T., 2015. Use of crop simulation modelling to aid ideotype design of future cereal cultivars. J. Exp. Bot., http://dx.doi.org/ $10.1093 / \mathrm{jxb} / \mathrm{erv} 098$.

Ruane, A., Cecil, L.D., Horton, R., Gordon, R., McCollum, R., Brown, D., Killough, B. Goldberg, R., Greeley, A., Rosenzweig, C., 2013. Climate change impact uncertainties for maize in Panama: farm information, climate projections, and yield sensitivities. Agric. For. Meteorol. 170, 132-145.

Schlenker, W., Roberts, M.J., 2009. Nonlinear temperature effects indicate severe damages to US crop yields under climate change. Proc. Natl. Acad. Sci. U. S. A 106, 15594-15598.

Siebert, S., Ewert, F., 2012. Spatiotemporal patterns of phenological development in Germany in relation to temperature and day length. Agric. For. Meteorol. $152,44-57$

Siebert, S., Ewert, F., 2014. Future crop production threatened by extreme heat Environ. Res. Lett. 9, 041001

Tao, F., Yokozawa, M., Zhang, Z., Hayashi, Y., Grassl, H., Fu, C., 2004. Variability in climatology and agricultural production variability in China in association with East Asian monsoon and El Niño Southern Oscillation. Clim. Res. 28, 23-30.

Tao, F., Zhang, Z., Liu, J., Yokozawa, M., 2009. Modeling the impacts of weather and climate variability on crop productivity over a large area: a new super-ensemble-based probabilistic projection. Agric. For. Meteorol. 149 $1266-1278$

Tao, F., Zhang, Z., 2010. Adaptation of maize production to climate change in North China Plain: quantify the relative contributions of adaptation options. Eur. J. Agron. 33, 103-116.

Tao, F., Zhang, Z., 2011. Impacts of climate change as a function of global mean temperature: maize productivity and water use in China. Clim. Change 105 409-432.

Tao, F., Zhang, Z., Zhang, S., Zhu, Z., Shi, W., 2012. Response of crop yields to climate trends since 1980 in China. Clim. Res. 54, 233-247.

Tao, F., Zhang, Z., Xiao, D., Zhang, S., Rötter, R.P., Shi, W., Liu, Y., Wang, M., Liu, F., Zhang, H., 2014a. Responses of wheat growth and yield to climate change in different climate zones of China, 1981-2009. Agric. For. Meteorol. 189-190, 91-104.

Tao, F., Zhang, S., Zhang, Z., Rötter, R.P., 2014b. Maize growing duration was prolonged across China in the past three decades under combined effects of temperature, agronomic management and cultivar shift. Glob. Change Biol. 20, 3686-3699.

Tong. P.Y., 1992. Maize Cultivation Zones of China. China agricultural science and technology press, Beijing, pp. 295-\$9.

Wang, X., Peng, L., Zhang, X., Yin, G., Zhao, C., Piao, S., 2014. Divergence of climate impacts on maize yield in Northeast China. Agric. Ecosyst. Environ. 196, 51-58.

Welch, J.R., Vincent, J.R., Auffhammer, M., Moya, P.F., Dobermann, A., Dawe, D., 2010. Rice yields in tropical/subtropical Asia exhibit large but opposing sensitivities to minimum and maximum temperatures. Proc. Natl. Acad. Sci. U. S. A. $107,14562-14567$

Xiao, D., Qi, Y., Shen, Y., Tao, F., Moiwo, J.P., Liu, J., Wang, R., Zhang, H., Liu, F., 2015. Impact of warming climate and cultivar change on maize phenology in the last three decades in North China Plain. Theor. Appl. Climatol., http://dx.doi.org/10. 1007/s00704-015-1450-x

Zhang, Z., Chen, Y., Wang, P., Zhang, S., Tao, F., Liu, X., 2014. Spatial and temporal changes of agro-meteorological disasters affecting maize production in China since 1990. Nat. Hazards 71, 2087-2100.

Zhang, Z., Song, X., Tao, F., Zhang, S., Shi, W., 2015. Climate trends and crop production in China at county Scale, 1980-2008. Theor. Appl. Climatol., http:// dx.doi.org/10.1007/s00704-014-1343-4. 